\section{artelogie}

\section{Artelogie}

Recherche sur les arts, le patrimoine et la littérature de l'Amérique latine

$12 \mid 2018$

Idiosyncrasie de l'indigénisme en Amérique latine.

Pluralité des sources et des appropriations extra-

latino-américaines

\title{
La fiesta del señor de Chalma y su contribución a la iconografía del muralismo mexicano
}

\section{Mauricio César Ramírez Sánchez}

\author{
(2) OpenEdition \\ Journals \\ Edición electrónica \\ URL: http://journals.openedition.org/artelogie/1929 \\ DOI: $10.4000 /$ artelogie. 1929 \\ ISSN: 2115-6395 \\ Editor \\ Association ESCAL \\ Referencia electrónica \\ Mauricio César Ramírez Sánchez, « La fiesta del señor de Chalma y su contribución a la iconografía del \\ muralismo mexicano », Artelogie [En línea], 12 | 2018, Publicado el 07 septiembre 2018, consultado el \\ 19 abril 2019. URL : http://journals.openedition.org/artelogie/1929; DOI : 10.4000/artelogie.1929
}

Este documento fue generado automáticamente el 19 abril 2019.

Association ESCAL 


\title{
La fiesta del señor de Chalma y su contribución a la iconografía del muralismo mexicano
}

\author{
Mauricio César Ramírez Sánchez
}

\section{Todo movimiento tiene un inicio}

1 En la actualidad al hacerse referencia al muralismo mexicano suele pensarse de manera inmediata en el arte que se origina como producto del movimiento revolucionario de 1910. Es decir, a todas aquellas obras cuya iconografía establece un vínculo con la lucha armada. No obstante, las primeras que se realizaron están alejadas de dicho discurso.

Cabe recordar que en 1920 Álvaro Obregón nombra a José Vasconcelos secretario de Educación Pública, quien dentro de su programa decidió apoyar la renovación artística, a través del muralismo. Entre sus primeras comisiones estuvo encargar a Roberto Montenegro y a Gerardo Murillo (Dr. Atl) la decoración del exconvento e iglesia de San Pedro y San Pablo. Las obras realizadas serán El árbol de la vida, del primero; y del segundo El hombre saliendo del mar, La ola, El murciélago y Paisaje. ${ }^{1}$

3 En éstas no puede decirse que esté presente la iconografía, que caracteriza al movimiento más adelante. De hecho, su contenido responde a una temática universal y en concordancia con los principios establecidos por José Vasconcelos. ${ }^{2}$ Sobre las primeras obras murales, Jean Charlot manifestó que, a pesar de que corresponden al inicio del renacimiento del muralismo mexicano, "contribuyeron sólo marginalmente a la formación de un estilo mexicano colectivo" (CHARLOT, 1985: p. 134). Es decir, estarían alejadas del discurso que comenzaría a gestarse en los muros de la Escuela Nacional Preparatoria, hoy Antiguo Colegio de San Ildefonso.

El mismo carácter universal tendrán las primeras obras que desarrollan las figuras emblemáticas del muralismo mexicano, Diego Rivera, David Alfaro Siqueiros y José Clemente Orozco. A éstos y otros artistas se les había encomendado, la decoración de la Escuela Nacional Preparatoria, como parte del proceso de reconstrucción del país. 
5 En el anfiteatro de este lugar Diego Rivera realiza La Creación usando la técnica de la encáustica. En ésta el artista establece una relación del hombre con la ciencia y las artes. A ello debe aumentarse la vinculación con la religión a través de las figuras del toro, águila, león y el querubín, que aparecen mezcladas entre el follaje. ${ }^{3}$

6 En cuanto a José Clemente Orozco puede hablarse de una primera etapa en la que realiza una serie de obras al fresco, en el corredor del primer piso del patio grande de la Preparatoria. La temática general era Los dones que recibe el hombre de la naturaleza, integrados por Cristo destruyendo su cruz, Los elementos, La lucha del hombre con la naturaleza y Maternidad. De estas obras Orozco sólo conservaría Maternidad y el rostro de Cristo, el resto fue destruido por él mismo, para dar paso a las temáticas nacionalistas.

7 David Alfaro Siqueiros trabajó en el espacio de la escalera del Colegio Chico de San Ildefonso, donde realiza Los elementos, Los mitos, El entierro del obrero sacrificado y El llamamiento a la libertad. En las dos primeras obras alude a un simbolismo alejado de toda cuestión revolucionaria; pero, a partir del Entierro del obrero sacrificado se enfoca a las cuestiones políticas, que caracterizaron su obra e incluso su vida. Esta obra recoge las problemáticas, que el país enfrentaba en esos momentos, por lo menos la lucha de los obreros en busca de que se respetaran sus derechos. ${ }^{4}$

\section{Fernando Leal y la búsqueda de la iconografía de un pueblo}

8 Como se vio los primeros temas que se desarrollaron dentro del muralismo, estaban muy alejados del nacionalismo, que se origina a partir de la Revolución, con que suele vinculársele. Es decir, la visión de un pueblo, representado por los grupos marginados y sus problemáticas. Correspondería iniciar con el cambio de temática a los demás artistas que colaboraban en la decoración de la Escuela Nacional Preparatoria. Fernando Leal realiza La Fiesta del señor de Chalma; Jean Charlot, La masacre en el templo mayor; Fermín Revueltas, Alegoría de la virgen de Guadalupe; y Alva de la Canal, El desembarco de la cruz. A ellos habría que agregar La fiesta de la santa Cruz, que Roberto Montenegro realizaba en la ex iglesia de San Pedro y San Pablo.

9 De este modo, aunque su presencia dentro del muralismo mexicano no resulta tan visible como la de Orozco, Rivera y Siqueiros, les corresponde haber introducido las temáticas que lo caracterizaran e identifican dentro del arte internacional. A través de sus obras se manifiesta la importancia que va a concederse a las tradiciones, principalmente en lo que se refiere a danzas y vestimentas. También comienzan a destacarse diversos símbolos, como sería la religión, con lo que busca unificarse una identidad. Otro aspecto sobresaliente será la utilización de pasajes de la historia nacional.

Un elemento de gran utilidad en la consolidación del movimiento muralista fue la creación del Sindicato de Trabajadores Técnicos, Pintores y Escultores, en 1922. En su manifiesto se dirigía a las clases oprimidas, representadas por el campesino, obrero y soldado, ${ }^{5}$ iconografía que posteriormente será recurrente en los muros. ${ }^{6}$

11 La organización tuvo una vida corta, pero puso a prueba los intereses de sus integrantes, lo que sería determinante en el camino que seguiría el muralismo. Con ello, no resulta extraño que atrajera la atención de un número importante de artistas de la época, que veían en él una forma de enfrentar los problemas sociales a través del arte. Así, había 
surgido el arte de la Revolución, que hasta la fecha sigue seduciendo a artistas de diversas latitudes. ${ }^{7}$

12 Los primeros años del muralismo pueden entenderse como un periodo de definición, en el que confluyen los intereses y formación de cada uno de los participantes. Pero, también, lleva a enfrentamientos en diferentes momentos.

13 Karen Cordero lo compara con una especie de laboratorio en que "se fraguaron una diversidad de estrategias para formular la pintura de alegoría y de historia, a partir de una concepción del arte como 'actor' social, como agente de cambio, pero sin un ideario ni un recetario fijo" (CORDERO, 1999: p. 233). Es decir, cada uno de los artistas seguía el camino que mejor les parecía. Con lo que fue conformándose un discurso que dio identidad y dirección al muralismo mexicano.

El acercarse a cada uno de los artistas que participaron en la primera etapa, ofrece la oportunidad de profundizar en los aportes que cada uno hizo a este movimiento artístico. Ello incluso permite arrojar luz sobre cada una de sus obras y enriquecer el conocimiento que se tiene sobre esta etapa del arte mexicano.

los iniciadores del muralismo mexicano, no valorado lo suficientemente. ${ }^{8} \mathrm{~A}$ lo que debe agregarse que ha tenido la mala fortuna, como ha sucedido a muchos artistas, que parte de su obra ha desaparecido; ${ }^{9}$ pero, a diferencia de otros, se conserva su primer mural, realizado en la antigua Escuela Nacional Preparatoria: La fiesta del señor de Chalma,$^{10}$ realizado entre 1922 y 1923. (Imag. 1) El acierto de esta obra, así como la de otros jóvenes muralistas, fue que pusieron sus ojos en las tradiciones e historia del pueblo mexicano, ${ }^{11} \mathrm{y}$ las trasladaron a los muros.

Para el momento en que participa en la Preparatoria puede considerársele como un artista joven, pues había nacido en 1900. No obstante, había participado en la Escuela de Pintura al Aire Libre de Coyoacán, de la que fue profesor y director. ${ }^{12} \mathrm{Al}$ momento en que José Vasconcelos lo convoca a integrase al proyecto, era considerado como una promesa dentro de la pintura.

El mural de Fernando Leal se localiza en el cubo de la escalera del patio grande de la antigua Escuela Nacional Preparatoria. Él mismo recordaría que por la amistad que tenía con el artista francés Jean Charlot, decidieron trabajar juntos. Por tal motivo escogieron el tercer tramo de la escalera principal, con lo que sus obras quedaron frente a frente. Con la finalidad de darle unidad el artista recordaría: "convinimos en los temas que íbamos a desarrollar, así como en la escala que habíamos de darle a las figuras, para que nuestra obra tuviera unidad" (LEAL, 1985: p. 185). Con ello, pretendían que sus murales no fueran obras aisladas, sino crear un discurso que le diera continuidad.

Jean Charlot en su obra La masacre en el templo mayor, (Imag. 2) se inclina por un pasaje histórico en el que hace hincapié en el momento en que Pedro de Alvarado y sus hombres atacan a los mexicas, cuando éstos se encontraban en una festividad, que incluía entre sus elementos la realización de bailes. El acontecimiento aparece simbolizado de una manera brutal, en el que cada cultura presenta su historia, sus costumbres, su organización social, religión, etcétera. Si bien, parece que una se impone sobre la otra en realidad se funden, y terminan por conformar una nueva nación. A través de esta obra Charlot pone como uno de los temas a explotar, por el muralismo y en general el arte de la época, el dramatismo de la historia, en la que la mexicana, en sus diferentes momentos, resultaba una fuente inagotable. 
mural La Creación. Sin embargo, sus consejos no les facilitaron el camino; lo que dejó un recuerdo negativo en varios de ellos. Fernando Leal comenta que éste les había dicho que, él había visto que los italianos amasaban la mezcla con las manos y la colocaban en la pared con los dedos. Ramón Alva de la Canal coincide con lo dicho por Leal, pues señala que durante una visita a su área de trabajo Rivera les dio una clase de cómo colocar el aplanado, lo cual consistió en tomar una porción de mezcla y colocarla con la palma de la mano en la pared. Lógicamente las propuestas de Diego Rivera fueron vistas como una manera de entorpecer su trabajo e incluso, como desconocimiento de las diferentes técnicas que podían practicarse en el muralismo.

esulta claro que Diego Rivera buscaba colocarse como cabeza visible del grupo, por lo que Fernando Leal consideró que debido a la "inexperiencia o al carácter un poco histérico de los artistas, todos trabajamos para destruirnos, y dejar que Diego Rivera alegremente se adueñara, durante años que todavía se prolongan, del campo de la pintura" (LEAL, 1985: p. 207). Al mismo tiempo, resultaba evidente la experiencia que éste 
había adquirido desde su salida de la Academia y su estancia en Europa, lo que supo aprovechar y canalizar en su propio beneficio.

Uno de los aportes del movimiento muralista mexicano será la recuperación del fresco. Aunque ello no estuvo exento de provocar discrepancias entre los artistas. Así, a pesar de que Jean Charlot y Fernando Leal habían convenido en trabajar juntos, tuvieron diferencias al decidirse por utilizar el fresco o la encáustica. El primero considerando los resultados que podían obtenerse del fresco, propuso que ambos realizaran sus obras bajo esta técnica, con lo que además de la relación temática lograrían una armonía cromática. Leal consideró que ello le llevaría a empobrecer el colorido que tenía pensado para su obra, por lo que se negó y terminó por distanciarse del artista francés. ${ }^{14}$

A pesar de las diferencias suscitadas entre Charlot y Leal conservaron el discurso que cada uno había planteado para sus obras. Como se comentó, el tema representado por el segundo alude a la idolatría persistente en las comunidades indígenas después de la conquista. La referencia la había tomado de un relato hecho por su hermano, sobre un incidente ocurrido en la sierra de Puebla. Éste consistió en que al estar unos danzantes bailando alrededor del nicho, de una imagen de la virgen, las vibraciones hicieron que la imagen cayera y dejara al descubierto una escultura de piedra.

Lo interesante del relato era que la llave del nicho era custodiada por los indígenas, con lo que era lógico que dicha escultura hubiera sido escondida por éstos. Fernando Leal, refiere que el mismo pasaje sirvió a Anita Brenner, para su libro Ídolos tras los altares. ${ }^{15}$

Fernando Leal retoma la idea, más que de la idolatría, del sincretismo que se da al unirse dos culturas distintas. Para ello aprovecha el mito de la aparición del Cristo de Chalma, ocurrida, según la tradición, el 1 de julio de $1539 .{ }^{16}$ Éste a su vez sustituyó el centro de adoración dedicado a Oztoteótl (dios de las cuevas, del pecado, juez y vengador), advocación de Tezcatlipoca negro. ${ }^{17}$ De esta manera, el centro de peregrinación prehispánico fue sustituido por el agustino. Tomando en consideración el culto que se desarrollaba en el lugar, no resulta extraño que la imagen colocada por los frailes españoles fuera un Cristo negro, como muchos de los que se encuentran en diferentes regiones de la república y parte de Centroamérica. ${ }^{18} \mathrm{En}$ algunos de los lugares en que en la actualidad se venera a los cristos negros, existe la coincidencia, con Chalma, de que los pueblos prehispánicos adoraban a una deidad de color negro. Ejemplo de ello es el Cristo de Esquipulas que sustituye al dios maya Ek Kampulá. ${ }^{19}$

En el caso del Cristo de Chalma Joaquín Sardo narra que después de que los padres de la región se enteran de que en una de las cuevas se adoraba a Oztoteótl, hablan con los habitantes para convencerlos de que adoraban a un falso dios. Posteriormente, "considerando, que ya conseguida la empresa de derrotar el ídolo, se les facilitaba más el camino para la reducción ciegos, trataron de volver luego a la cueva, acompañados de los ocuyltecas mismos, para que quitada aquella piedra de escándalo, y bendiciendo ellos la cueva, se colocase en el mismo lugar la Santa Cruz." (SARDO, 1810: p.18) Días después y acompañados de algunos indígenas, los sacerdotes se dirigieron a la cueva, con la intención de colocar una nueva cruz, pero a su llegada encontraron al Cristo. A través de dicha narración, puede establecerse que al suprimir una imagen por otra se buscaba que los indígenas vieran en la nueva a un dios más poderoso, pero al que se le podían seguir rindiendo las mismas reverencias que al anterior.

La obra de Fernando Leal destaca las peregrinaciones que se realizan al santuario de Chalma. Por ello, junto al Cristo aparece la figura de un sacerdote custodiando la imagen. 
En este último se recuerda el origen de la religión, pues a diferencia del resto de las figuras que aparecen en la obra, tiene tez clara y está atento a lo que se desarrolla alrededor del Cristo. Incluso es probable que el sacerdote que aparece en la escena se corresponda con el encargado del templo en el momento que se desarrolla el mural; pues, como se verá más adelante Fernando Leal se preocupa por investigar los elementos que compondrían su obra.

Aunque lo primordial es presentarse ante el Cristo, para realizar una súplica, la que en muchas ocasiones se hace de rodillas. También era fundamental acompañar la petición con una ofrenda. Por ello se entiende que a los pies del Cristo se observen flores, frutos y pan, que, los feligreses le han llevado. Algunas mujeres se encuentran arrodilladas ante la imagen, en actitud de veneración, que es complementada con los cirios que algunas portan.

31 Cabe señalar que la importancia que tiene Chalma como lugar de peregrinación, y que se destaca en el mural, era una tradición que ya se tenía desde la época prehispánica, pues como se ha señalado a ese lugar se acudía a adorar a Oztoteótl. Sobre la importancia de dichas peregrinaciones Joaquín Sardo comenta: "era mucha la devoción (mejor diríamos superstición) y grande la estima, que su engañada ceguedad hacía de este ídolo, y conforme a ella era el enorme concurso de naturales, que de toda la comarca, y que de los más remotos climas venían a adorarle y ofrecerle torpes víctimas, y pedirle para sus necesidades, el favor y exilio." (SARDO, 1810: p. 4) Como puede verse el sentido ritual que rodeaba a Oztoteótl, se traslada al Cristo, podría decirse que fue una simple sustitución, pero de fondo lo que se ve son dos maneras distintas de concebir la religión. Así, para los españoles había una sola; mientras que para los indígenas no existía la intolerancia religiosa, por lo que podían aceptar los dioses provenientes de otros pueblos, sobre todo cuando éstos demostraban ser más poderosos. En gran medida, puede decirse que dicha libertad de culto fue lo que sobrevivió.

Fernando Leal aprovechó la inclinación de la escalera, para situar en esta sección, a los peregrinos que se encuentran descansando, del camino recorrido. Con ello, más que desarrollarse la escena dentro de la iglesia, ésta se da en el atrio del templo. De este modo, el artista busca integrar la obra a la arquitectura, aprovechando todos los espacios, lo que se vuelve un elemento de referencia para el movimiento.

Los personajes, que se encuentran descansando, con los sombreros a la espalda recuerdan su obra Campamento zapatista, de 1921. (Imag. 3) Sobre ésta recordaría: "un día emprendí un cuadro de grandes dimensiones, en el estudio de la Escuela de Coyoacán, el cual representaba un campamento zapatista" (LEAL, 1985: p. 198) Será durante la realización de ésta que José Vasconcelos lo visite en su estudio y lo invite a incorporarse al proyecto de la preparatoria, por lo que no sería extraño que quisiera dejar huella de ese momento en su obra. Sobre ello recordaría, "en aquel momento, era yo el primero que pintaba una escena de la Revolución, con gran disgusto de todo el mundo, como ya dije, y muy especialmente de Ramos Martínez, quien no concebía que se pudiera pintar un indio con cananas y pistola, cuando era más 'millet' pintarlo con una olla entre las manos."(LEAL, 1990: p. 174)

El elemento que marca la relación entre el mural y el cuadro es la presencia de una estampa de la virgen de Guadalupe, sobre uno de los sombreros, en cada una de las obras. En Campamento zapatista aparecen cuatro hombres formando un semicírculo, de frente; en el mural también se ve a cuatro hombres, pero de espaldas. Por tanto, puede decirse que conserva el interés por los temas nacionales, que ya estaba practicando. 
Dentro del grupo de peregrinos destaca la presencia de tres niñas vestidas de blanco, con una cinta roja ceñida a la cintura. Cada una porta una corona de flores en la cabeza que alude a la tradición de que todo el que visita por primera vez el santuario debe colocarse una. ${ }^{20}$ También cabría suponer que la razón de que vistan de blanco se debe a que van a cumplir con un sacramento religioso, como la primera comunión, que suelen ser comunes en las fiestas patronales de cada localidad. Este grupo de infantes pueden relacionarse con la danza de los arcos, en particular la niña que mira de frente, pues sostiene una tira con flores que al doblarse forma un arco. ${ }^{21}$ Posteriormente Diego Rivera la retoma, en el tablero denominado La danza de los listones, que forma parte del patio de las fiestas de la Secretaría de Educación Pública.

Puede decirse que Diego Rivera absorbió los elementos que fueron propuestos por los diferentes artistas. Sobre el planteamiento de Fernando Leal, Jean Charlot comentaría: “el prototipo de los patios de la Secretaria -llenos de la representación de fiestas populares, peregrinaciones, danzas rituales, con acento en los trajes y costumbres pintorescas-, es la obra de Fernando Leal, Fiesta del Señor de Chalma, cuya concepción fue simultánea a la ejecución de la italianizada Creación" (CHARLOT, 1985: p. 185). Puede decirse que en la obra de Leal se percibe un sentido antropológico, a través del cual se emprende un rescate de las tradiciones nacionales, que serán de gran importancia durante el proceso de reconstrucción del país, pues mediante ello se da contenido al nacionalismo que se estaba creando.

Los que ocupan la mayor parte del mural son los danzantes y los músicos. En cuanto a los últimos se observa a tres personajes, uno toca un violín, uno más la flauta y el último un tambor, la vestimenta de éstos destaca por su colorido. En ello, está presente una variante más del sincretismo, pues el violín llega al continente a partir de la conquista europea, mientras que los otros dos instrumentos son reminiscencias del mundo prehispánico.

El traje de los danzantes, también destaca por su colorido, éstos son admirados por los peregrinos que se encuentran en el atrio. Sobre estos personajes Fernando Leal escribió: "Con objeto de documentarme sobre los trajes y movimientos de los danzantes, procuré la amistad de un capitán de danzas, quien me llevó a presenciar los ensayos de su congregación. También Luciana, una modelo india de la que había yo pintado muchos cuadros, me llevó a su pueblo, donde pude tomar gran cantidad de datos" (LEAL, 1985: p. 201). En ello está presente la necesidad de que la obra refleja una realidad y en la que confluyen, alrededor del Cristo, ciertas costumbres y tradiciones.

Importante resulta la mención de Luciana, también conocida como Luz Jiménez, la cual no sólo fue modelo de Fernando Leal, sino también de José Clemente Orozco, Diego Rivera, Jean Charlot, David Alfaro Siqueiros, Luis Nishizawa y Pablo O'Higgins. La trascendencia que esta mujer alcanza dentro del arte mexicano se puso de manifiesto en la exposición que se le dedicó en el Museo Casa Estudio Diego Rivera y Frida Kahlo, a finales de 1999. ${ }^{22}$

Leal representa a los danzantes con colores chillantes y penachos de grandes plumas. Sus rasgos indígenas dan la apariencia de que éstos portan mascaras, aunque en dos de ellos es clara la utilización de éstas, con lo que se establece un diálogo directo con los guerreros mexicas que aparecen en La masacre en el templo mayor. ${ }^{23}$ Con ello, da a entenderse que la cultura prehispánica ha logrado sobrevivir a los embates de la conquista, lo que resulta notorio en el aspecto cultural.

Una figura que resulta fundamental dentro del mural es el hombre que se encuentra parado y observa hacia el espectador. En éste además de sus rasgos indígenas, resalta su 
mirada perdida como si se encontrara en una especie de trance, producido por la danza. En éste se encuentra una vez más la vinculación al mundo prehispánico, pues resulta claro que el artista está aludiendo a la advocación de Tezcatlipoca negro, con lo que se entendería que mire hacia el espectador o a la conquista, representada en el mural de Jean Charlot, a la que ha logrado sobrevivir. ${ }^{24}$

Este personaje también puede ser el capitán que apoya a Leal con información. La conveniencia de usar este personaje radica en que las congregaciones de danzantes eran organizaciones disciplinadas y se organizaban jerárquicamente. Los rangos que se utilizaban eran generales, capitanes, alférez y soldados. ${ }^{25}$ Cada grupo contaba con un capitán que tenía que cumplir con funciones específicas.

En lo que se refiere a La danza de los arcos "disciplinaba a los participantes. Traía consigo una ardilla y un chicote, la cara la tenía de negro, y con cierta frecuencia golpeaba, o fingía que golpeaba a los danzantes que se equivocaban en los pasos, y que hacían acreedores al castigo" (BALLESTEROS, 1990: p. 39). Aunque la figura del capitán o dirigente también se encuentra presente en la versión española, no presenta los atributos que se mencionan en la nota y que vuelven a referir al sincretismo, sobre todo en lo que se refiere a que el capitán llevaba el rostro pintado.

Otro elemento que complementa la información que Fernando Leal, pudo obtener de su cercanía con los grupos de danzantes es la presencia de los estandartes. Así, en uno de ellos puede leerse: "Estandarte de la asociación de Danzantes del Milagroso (sic) Sr. De Chalma. Felipe Bela... per Capitán," en otro más se distingue "Nuestro padre Jesús a pueblo de San Acopilco." En este punto resulta evidente una vez más el sincretismo, pues: cabe recordar que éstos ya eran utilizados antes de la llegada de los españoles, que también los usaban. Ahora, "con el estandarte se defiende un linaje y se trata de demostrar la antigüedad de los miembros de una familia en la danza y la nobleza de su escudo, pero tiene más un carácter político social que religioso" (GALOVIC, 2002: p. 485). Es decir, cada estandarte representa a una congregación de danzantes y los liga a un santo en particular. La presencia de éstos, en el mural, da una idea de los diferentes grupos que visitaban dicho recinto y que es probable que Fernando Leal haya podido observar directamente.

Llama la atención que los danzantes lleven un palo de cuya parte superior se encuentran sujetas diversos listones de colores, que remite a la danza de las cintas. Ésta actualmente se realiza, con sus respectivas variantes, en Yucatán, Guerrero, Estado de México, Colima, Oaxaca, Hidalgo, Tlaxcala y Puebla. Si bien, su origen es difícil de determinar, lo cierto es que en todas ellas se coincide en que se coloca un palo alto de cuya punta están sujetas diversas cintas de colores. Cada una de éstas es tomada por uno de los bailarines que van dando vueltas alrededor del palo, al tiempo que se cruzan uno con otro, lo que lleva a formar un tejido de colores. Cuando sólo queda un trozo de las cintas, las personas bailan a la inversa, con lo que el tejido se desase.

Lo interesante en el mural de Fernando Leal resulta que si bien se alude a "La danza de las cintas," la vestimenta de los personajes (falda sobre pantalón, penacho y los colores chillantes) recuerdan a los concheros. En dichos danzantes se reúnen tanto elementos precolombinos como españoles y su presencia se manifiesta de diferentes formas en la república mexicana.

47 Como en todo grupo de danzantes son encabezados por un capitán que "coordina la organización de las peregrinaciones y de todo lo relacionado con las actividades rituales, 
es el poseedor del conocimiento tradicional y esotérico, de la música, de los pasos de la danza y casi siempre es curandero" (GONZÁLEZ, 2005: p. 54). De esta manera, cobra sentido el interés que Fernando Leal buscó establecer con el capitán de danza, pues obtiene de manera directa los conocimientos que habían pasado de generación en generación y logra plasmarlos en su obra.

\section{Conclusión}

A manera de conclusión puede decirse que todos los elementos que componen La fiesta del señor de Chalma, se encuentran plenamente justificados. Es decir, el artista llevó a cabo una amplia investigación, de ahí el sentido antropológico de la obra, a través de la cual pudo determinar todo lo que utilizaría. Este acercamiento, directo, a las tradiciones mexicanas le lleva a romper con los moldes renacentistas, que habían utilizado los demás muralistas en sus obras.

Con ello, hace que el muralismo dirija su mirada hacia las tradiciones mexicanas, pero utilizando como modelo a los que mejor las conocían y conservaban: la población indígena. Resulta claro, que en el proceso de reconstrucción al que había entrado el país, en esos años, después de la lucha armada, todos esos elementos serían revalorados.

Al elegir la festividad del Cristo de Chalma, para contraponer a la visión de la conquista que Jean Charlot había realizado en el muro de enfrente, busca ejemplificar el sincretismo que se da a partir del choque de dos culturas. Pero, no establece un discurso triunfalista, pues las personas menos favorecidas siguen sometidas al peso de la religión. Con lo que la música y la danza son una manera de confrontarla, al tiempo que dan pauta para liberarse del peso del pasado. Por ello, queda de manifiesto, a través de los estandartes la importancia de que los conocimientos de dichas tradiciones pasen de generación en generación. De esta manera, el discurso establecido por Fernando Leal, en La fiesta del señor de Chalma, sigue estando vigente.

\section{IMÁGENES}

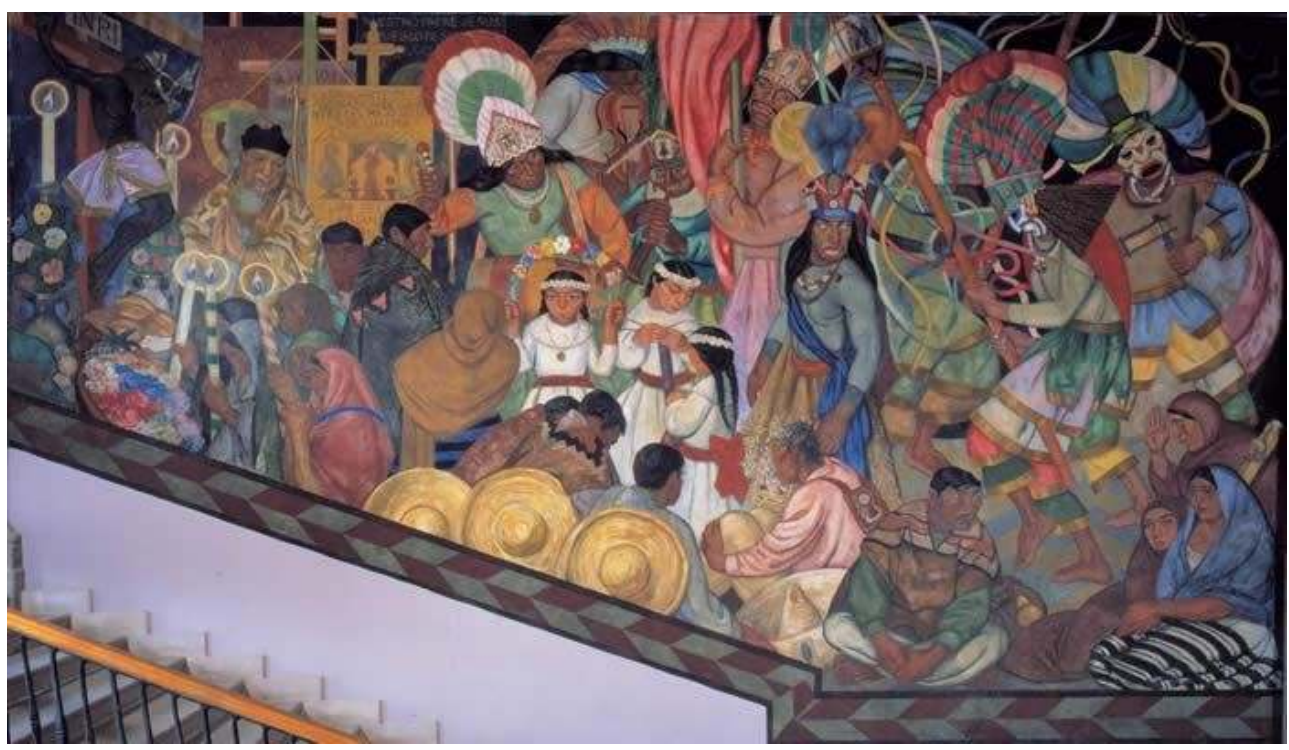

Imag. 1. Fernando Leal, La fiesta del señor de Chalma, 1923. 


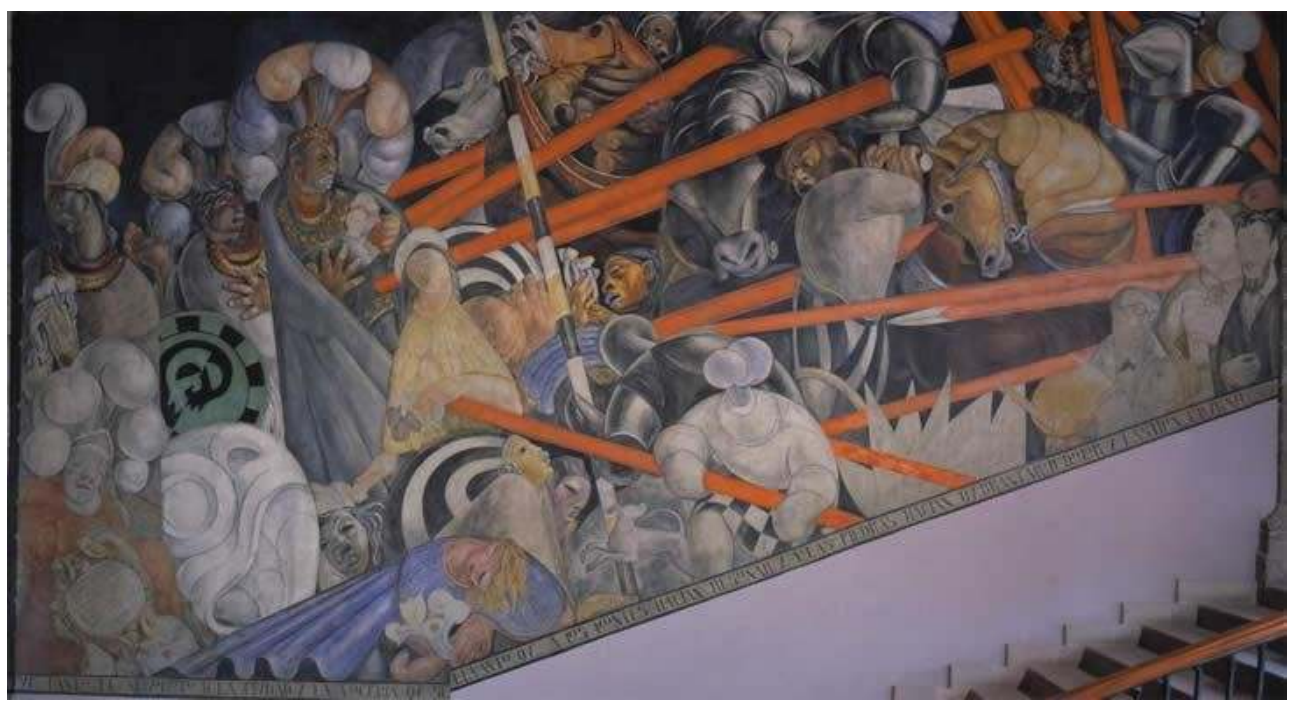

Imag. 2. Jean Charlot, La matanza del templo mayor, 1922.

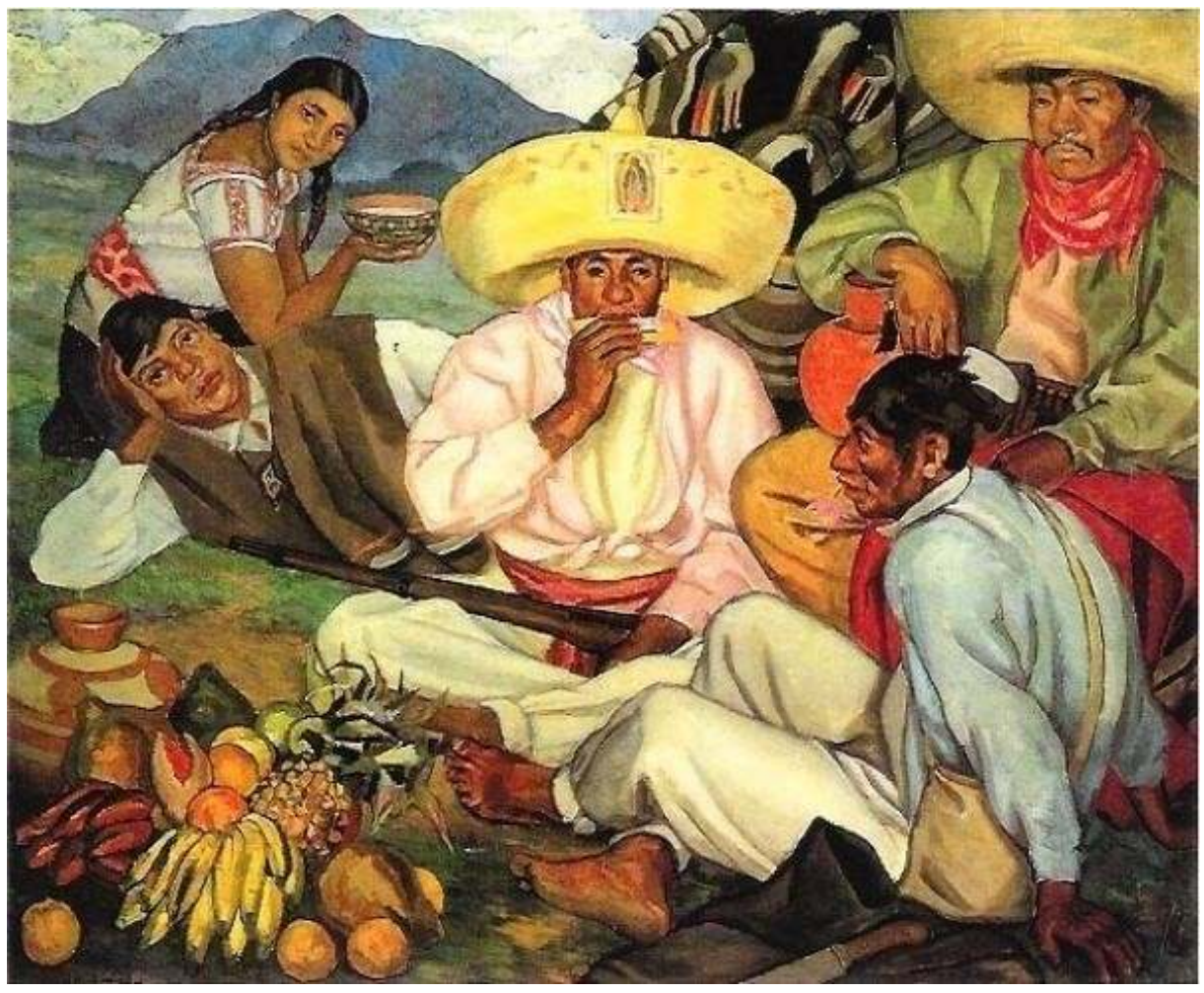

Imag. 3. Fernando Leal, Campamento zapatista, 1921.

\section{BIBLIOGRAFÍA}

ALFARO SIQUEIROS David, Me llamaban el coronelazo, México, Grijalbo, 1977. 
ARIAS Patricia, "Exvoto y especialidad en el siglo XIX. La apropiación social de una práctica misionera," en HERNÁNDEZ MADRID Miguel J. y JUÁREZ CERDI Elizabeth, [editores], Religión y cultura: crisol de transformaciones, Zamora, Michoacán, El Colegio de Michoacán, 2003.

BALLESTEROS Víctor M., "Historia y leyenda del Cristo de Tezaquiapan," en: Tiempo Nuestro. Investigación científica y tecnológica, Hidalgo, Universidad Autónoma de Hidalgo, 1990.

BRENER Anita, Ídolos tras los altares (traducción Sergio Mondragón), México, Domés, 1985.

CHARLOT Jean, El renacimiento del muralismo mexicano, México, Dumas, 1985.

CORDERO REIMAN Karen, "La invención del muralismo mexicano. Bosquejo para un acercamiento analítico," en Memoria. Congreso Internacional de Muralismo, México, Universidad Nacional Autónoma de México - Consejo Nacional para la Cultura y las Artes, 1999, pp. 231-240.

Diego Rivera: obra mural completa, Koln, Tachen, 2007, 672p.

DÍEZ DE ARRIBA Luis, Esquipulas: 400 años: fe blanca en un Cristo negro, Guatemala, s/e, 1997.

FERNÁNDEZ Justino, Arte moderno y contemporáneo de México, 2ed., México, Universidad Nacional Autónoma de México, 2001.

FLORES Tatiana, "Murales estridentes. Tensions and Affinities between Estridentismo and Early Muralism," en Mexican Muralism. A Critical History, edited by Alejandro Anreus, Leonard Folgarait and Robin Adèle, Berkeley, University of California Press, 2012, p. 108-124.

GALOVIC Jelena, Los grupos místico-espirituales de la actualidad, México, Plaza y Valdez, 2002.

GONZÁLEZ MATUTE Laura, Escuelas de pintura al aire libre y centros populares de pintura, México, Instituto Nacional de Bellas Artes, 1987.

GONZÁLEZ TORRES Yólotl, Danza tu palabra: la danza de los concheros, México, Consejo Nacional para la Cultura y las Artes -Plaza y Valdez, 2005.

ISLAS GARCÍA Luis, Fernando Leal, México, Ediciones de Arte, 1951.

LEAL Fernando, "Reminiscencias de Fernando Leal," en CHARLOT Jean, Renacimiento del muralismo mexicano, México, Domés, 1985, p. 195-207.

LEAL Fernando, El arte y los monstruos, México, Instituto Politécnico Nacional, 1990.

LÓPEZ OROZCO Leticia, “Xavier Guerrero entre el pincel, la línea y la acción," en Xavier Guerrero [1896-1974] de piedra completa, México, Instituto Nacional de Bellas Artes, 2012, pp.

Luz Jiménez. Símbolo de un pueblo milenario 1897-1965, México, Consejo Nacional para la Cultura y las Artes, 2000.

MANRIQUE Jorge Alberto, “Los primeros años del muralismo," en Historia del arte mexicano, México, Salvat, 1982, Tomo 13, pp. 1838-1855.

Memoria. Congreso Internacional de Muralismo, México, Universidad Nacional Autónoma de México Consejo Nacional para la Cultura y las Artes, 1999.

MICHELI Mario de, Siqueiros, México, Secretaría de Educación Pública, 1985.

NAVARRETE Carlos, En la diáspora de una devoción: acercamiento al estudio del Cristo Negro de Esquipulas, México, Universidad Nacional Autónoma de México, 2013.

OROZCO José Clemente, Autobiografía, México, Planeta-Joaquín Mortiz, 200.

ORTIZ GAITÁN Julieta, Entre dos mundos. Los murales de Roberto Montenegro, 2ed., México, Universidad Nacional Autónoma de México, 2009. 
REIFLER BRICKER Victoria, El Cristo indígena, el rey nativo, México, Fondo de Cultura Económica, 1989.

RODRÍGUEZ PRAMPOLINI Ida [coordinadora], Muralismo mexicano 1920-1940. Catalogo razonado, México, Fondo de Cultura Económica-Universidad Veracruzana, 2012.

ROMERO QUIROZ Javier, Tezcatlipoca es el Oztoteotl de Chalma: toponimia, México, Gobierno del Estado de México-Dirección de Turismo, 1957.

ROSALES Sofía, "Comentario a la ponencia de John Charlot," en: Memoria. Congreso Internacional de Muralismo, México, Universidad Nacional Autónoma de México - Consejo Nacional para la Cultura y las Artes, 1999, p. 300-302.

SARDO Joaquín, Relación histórica y moral de la portentosa imagen de N. Sr. Jesucristo crucificado aparecido en una de las cuevas de S. Miguel de Chalma, hoy real convento y santuario de este nombre, de religiosos ermitaños de N.G.P. y Doctor S. Agustín, en esta Nueva España, y en esta provincia del Santísimo nombre de Jesús de México, Nueva España, Impreso en Casa de Arizpe, 1810.

SUÁREZ Orlando S., Inventario del muralismo mexicano, México, Universidad Nacional Autónoma de México, 1972.

TIBOL Raquel, Palabras de Siqueiros, México, Fondo de Cultura Económica, México, 1996.

\section{NOTAS FINALES}

1. Sobre la obra del primer artista puede verse (ORTIZ, 2009); para el segundo (SUÁREZ, 1972: p. 76). También resulta fundamental (RODRÍGUEZ, 2012) En este último se señala que el Dr. Atl realiza doce secciones bajo el título general de La bella furia del mar, que comprendía: El sol, La lluvia, El viento, La luna, El hombre que salió del mar, El titán, El vampiro, La noche, La ola y tres paisajes marinos.

2. Sobre esta etapa José Clemente Orozco, comentaría: "hubo un periodo de preparación durante el cual se hicieron muchos ensayos y tanteos, siendo las obras puramente decorativas y con alusiones muy tímidas a la historia, a la filosofía o a otros temas diversos," (OROZCO, 2002: p. 61). Esa búsqueda les llevaría a ofrecer en sus obras los resultados de sus propias inquietudes.

3. En el congreso San Ildefonso, cuna del Muralismo Mexicano: reflexiones historiográficas y artísticas, que se celebró en 1998, se hacía hincapié en que una de las obras sobre las que más se ha escrito es La Creación a la que Luis-Martín Lozano dedicaría la ponencia "Reinterpretaciones en torno a La Creación de Diego Rivera: recuento historiográfico," que fue incluida en: Memoria. Congreso Internacional de Muralismo, México, UNAM-CONACULTA, 1999, pp. 75-88. Claro está que desde ese año los estudios que se han referido a esta obra se han seguido multiplicando, uno de ellos es Diego Rivera: obra mural completa, Koln, Tachen, 2007, 672p. En este libro, enriquecido por el material iconográfico que se incluyó, se hizo un recuento de la obra muralista de Diego Rivera.

4. Mario de Micheli señala que en especial se vio influenciado por las huelgas que se suscitaron en 1922, lo que le llevó a cambiar el discurso de sus primeras obras. (MICHELI, 1985: pp. 48-49) El propio artista comenta que se da un giro en la temática de sus obras, aunque no alude a las problemáticas obreras, pero aprovecha para establecer que fue el introductor de la "expresión etnográfica," (ALFARO, 1977: p. 199).

5. En lo referente al arte el Manifiesto del Sindicato señala que éste, debe socializarse para hacer frente al individualismo y agregaba: "repudiamos la llamada pintura de caballete y todo el arte de cenáculo ultraintelectual, por aristocrático, y exaltamos las manifestaciones de arte monumental, por ser de utilidad pública" (TIBOL: 1996: p. 24). Resulta interesante que en el discurso los diferentes artistas parecían comulgar con lo sostenido por el manifiesto, pero en la 
práctica no se respetaba. Sin embargo, hace evidente la importancia que se le concedió al muralismo.

6. El manifiesto también señalaba que: "el triunfo de las clases populares traerá consigo un florecimiento, no solamente en el orden social, sino un florecimiento unánime de arte étnica, cosmogónica e históricamente trascendental en la vida de nuestra raza, comparable al de nuestras admirables civilizaciones autóctonas." "Manifiesto del sindicato de obreros técnicos, pintores y escultores," El Machete, México, segunda quincena de junio de 1924. Tomado de (TIBOL, 1996: pp. 23-26). Lo planteado por el manifiesto no implica un retroceso, más bien era el establecimiento de un nuevo rumbo, que tendría que manifestarse en el arte.

7. Ejemplo del impacto que el muralismo mexicano ha tenido en el extranjero ha sido estudiado a través del boletín Crónicas. El muralismo, producto de la Revolución mexicana en América, que se edita en el Instituto de Investigaciones Estéticas de la Universidad Nacional Autónoma de México.

8. Luis Islas García establece que "desde los días en que por iniciativa de Vasconcelos renació la decoración de los edificios públicos de México, Leal ocupó un puesto junto a muchos que no han logrado sobrevivir," (ISLAS, 1951: p. 1). Puede decirse que con el paso de los años continúa desarrollando obras murales, lo que lo mantiene dentro del movimiento.

9. Además del mural al que se dedica el presente ensayo realizó: La escala de la vida, en 1927; La epopeya bolivariana, de 1930 a 1933; Neptuno encadenado, en 1935; Fantasmagorías, en 1940; Los insurgentes, en 1941; El triunfo de la locomotora y la Edad de la máquina, en 1943; La glorificación de santo Domingo de Guzmán, de 1944 a 1947; La decoración de la capilla del Tepeyac, en 1947; y La danza de Xochiquetzalli, en 1958.

10. El mural también es mencionado simplemente como Los danzantes de Chalma, ver (SUÁREZ, 1972: 187) y (GARCÍA, 1951: p. 1).

11. Un estudio que hace hincapié en la manera en que va consolidándose el movimiento muralista puede verse en (MANRIQUE, 1982).

12. Sobre la presencia de Fernando Leal en la Escuela de Pintura al Aire Libre de Coyoacán, puede verse (GONZÁLEZ, 1987), (SUÁREZ, 1972) y (LEAL, 1990).

13. En este sentido será importante la participación de Xavier Guerrero, en lo que se refiere a las técnicas que se aplicarían en el muralismo al respecto Leticia López Orozco, comenta: "pensemos también en Guerrero como uno de los pioneros en el conocimiento de las técnicas de la pintura mural empleadas por primera vez en la entonces Escuela Nacional Preparatoria, hecho que quedó plasmado en las referencias que Diego Rivera, David Alfaro Siqueiros y Jean Charlot hicieron de sus aportaciones y de su experiencia con el fresco tradicional, utilizado en la decoración de cielos rasos y corredores de las casas de las familias adineradas en el norte de nuestro país, o con el método que los pintores populares empleaban para decorar pulquerías." (OROZCO, 2012: p.) De tal modo, sus conocimientos fueron aprovechados por diferentes artistas, con los que fungió como ayudante.

14. El texto escrito por Fernando Leal, por petición del propio Jean Charlot, le sirvió para establecer una nueva cercanía con el antiguo amigo y reconocer las equivocaciones que había cometido en el pasado, sin embargo la historia ya estaba escrita.

15. Anita Brenner, Ídolos tras los altares (trad. Sergio Mondragón), México, Domés, 1983, 400p. Este libro se publicó por primera vez, en inglés, en 1929.

16. Un relato interesante sobre la aparición del Cristo de Chalma es el de: Joaquín Sardo, Relación histórica y moral de la portentosa imagen de N. Sr. Jesucristo crucificado aparecido en una de las cuevas de S. Miguel de Chalma, hoy real convento y santuario de este nombre, de religiosos ermitaños de N.G.P. y Doctor S. Agustín, en esta Nueva España, y en esta provincia del Santísimo nombre de Jesús de México, Nueva España, Impreso en Casa de Arizpe, 1810, 386p.

17. Sobre la importancia de Tezcatlipoca puede verse (ROMERO, 1957) Cfr. (ARIAS, 2003: p.92). En este último se dice: "el otro santuario más antiguo y afamado del centro del país es el del Santuario de Chalma, que se localiza en el pueblo de Malinalco, al sur del Estado de México. Como 
en el caso del Tepeyac, la cueva de Chalma era importante lugar de peregrinación en la época prehispánica. De allí que la antigua, abundante y densa población indígena haya entrado seguramente muy pronto en los planes de evangelización de los monjes agustinos." Cabe decir, que como medida de control se toleran algunas tradiciones, que resultaban inofensivos para los clérigos. En este caso se conserva el lugar de adoración, sustituyendo la imagen por alguna con las mismas características.

18. Sobre la importancia de los cristos negros puede verse (DAVIDSON, 2014) También es interesante el estudio de (REIFLER, 1989), en que se hace un seguimiento de los cristos en la zona maya.

19. Sobre la importancia del culto hacía este Cristo pueden verse (NAVARRETE, 2013) y (DÍEZ, 1997). Interesante resulta que en el caso del Cristo de Esquipulas se establece que después de la evangelización y aprovechando una buena cosecha, será la propia comunidad la que encargue la realización de la imagen.

20. Yólotl González Torres comenta sobre el ritual que siguen los que visitan por primera vez Chalma: "cerca de Chalma hay un viejo ahuehuete, debajo del cual nace el principal manantial que forma el río Chalma, con cuya agua se bañan o se untan el cuerpo las mujeres que desean tener hijos. Cuando los peregrinos, que van por primera vez a Chalma, llegan frente al árbol, sus padrinos les colocan en la cabeza una corona de flores y después bailan," (GONZÁLEZ, 2005: p. 104). No deja de llamar la atención que dentro del ritual, resulte fundamental el papel que juega el baile.

21. La danza de los arcos es de origen asturiano y "era ejecutada por niños y jóvenes; los arcos que llevaban en las manos estaban hechos de varas de membrillo y adornados con flores de papel de china, sus tocados lucían plumas y espejos," (BALLESTEROS, 1990: p. 39). Al pasar a México, el baile comenzó a tener diferentes variantes, dependiendo del lugar en que se practicaba, pues lo mismo puede encontrarse en Hidalgo, Puebla o Estado de México.

22. A la muestra la acompañó el catálogo Luz Jiménez. Símbolo de un pueblo milenario 1897-1965, México, Consejo Nacional para la Cultura y las Artes, 2000, 154p. En éste se reúnen todas aquellas obras en las que esta mujer sirvió de arquetipo.

23. Karen Cordero Reiman comenta sobre el diálogo sostenido por las dos obras "las carasmáscaras de los líderes mexicas se comunican lateralmente con las máscaras de los danzantes de Chalma en el mural de enfrente, pero éstos se integran no en una narrativa dramática, sino en un tapiz pictórico, organizado sobre todo a partir de colores vívidos y contrastantes," (CORDERO, 1999: p. 238). Cabe decir, que la resistencia por medio de las tradiciones, que se reflejan en la obra de Fernando Leal, manifiestan un dramatismo cultural.

24. Sobre este personaje Tatiana Flores propone: “Leal's mural invokes Mexico's primitive cultures but grounds them in the present day by depicting a self-portrait in one of the dancers, positioned two-thirds of the way from the left and wearing a headdress with three feathers in primary colors, who stares confrontationally out of the composition." (FLORES, 2012: p. 115) Ello resulta discutible si se considera que el propio Fernando Leal no señala nada en los textos de su autoría (LEAL, 1985) y (LEAL, 1990), a pesar de que reconoció cuales fueron sus fuentes directas para obtener la información necesaria sobre las danzas, destacando la amistad con un capitán de danzantes. (LEAL, 1985: p. 201) Cabe decir, que en el muro de enfrente Jean Charlot no tuvo inconveniente en incluir su retrato y el de algunos amigos, entre los que incluyó a Fernando Leal con barba. Sobre este punto Sofía Rosales dice: "a diferencia de obras religiosas europeas donde los donantes aparecen retratados como parte de la escena, el tema histórico Masacre en el Templo Mayor le otorga un sentido diferente a la presencia de Charlot, Fernando Leal, Diego Rivera, Xavier Guerrero (o Luis Escobar) y el niño... No son solamente los amigos del pintor, sino testigos históricos, estudiosos del pasado mexicano y críticos del momento crucial en que vivían cuando Charlot los eternizó en su mural." (ROSALES, 1999: 302) Claro está que, con ello, no se 
invalida la utilización de modelos para la realización de las composiciones, pero habría que decir que una vez que ésta está concluida reclama su independencia.

25. Yólotl González Torres, señala que este tipo de rangos se retoman de la organización del antiguo ejército español. (GONZÁLEZ, 2005)

\section{RESÚMENES}

Después del movimiento armado que estalla en México en 1910, el país está en un proceso de restauración, que se manifiesta en lo político, social y cultural. En el último aspecto resulta fundamental el arte, que alcanza su máxima expresión a través del muralismo. En éste será fundamental la iconografía de que se nutre, pues se revalora la historia, pero en especial el pasado indígena. Así, se resaltan tradiciones y costumbres, que le dan una identidad propia al arte mexicano.

Après le mouvement armé qui a explosé au Mexique en 1910, le pays est en cours de restauration, qui se manifeste politiquement, socialement et culturellement. Dans le dernier aspect, l'art est fondamental, qui atteint son expression maximale à travers le muralisme. En cela, l'iconographie de ce qui est nourri sera fondamentale, car l'histoire est réévaluée, mais surtout le passé indigène. Ainsi, les traditions et les coutumes sont mises en évidence, ce qui donne à l'art mexicain sa propre identité.

\section{ÍNDICE}

Mots-clés: muralisme, danseurs, indigènes, traditions, révolution mexicaine

Palabras claves: muralismo, danzantes, indígenas, tradiciones, Revolución Mexicana

\section{AUTOR}

\section{MAURICIO CÉSAR RAMÍREZ SÁNCHEZ}

Universidad Nacional Autónoma de México. Facultad de Estudios Superiores Cuautitlán. Diseño y Comunicación Visual a Distancia. Doctor en Historia del Arte 